\title{
EDITORIAL
}

\section{Foreword: Starting JMC}

\author{
Linqiang Pan ${ }^{1}$. Gheorghe Păun ${ }^{2} \cdot$ Gexiang Zhang ${ }^{3}$
}

Published online: 22 March 2019

(c) Springer Nature Singapore Pte Ltd. 2019

The road of one thousand li starts with a single step. (Confucius)

Building a bridge between computer science and natural sciences, natural computing is the field of research that investigates human-designed computing inspired by nature as well as computing taking place in nature. It investigates models and computational techniques inspired by nature, and also it investigates, in terms of information processing, phenomena taking place in nature $[6,11]$. Natural computing is well developed theoretically, tremendously useful in applications, still promising fundamental progresses (see, e.g., the recent spectacular steps ahead in neural computing/deep learning, in conjunction with cloud computing, connectivity, big data-all these are considered basic ingredients of what is already called The Fourth Technological Revolution).

As a vigorous branch of natural computing, initiated by Prof. Păun [8], Membrane Computing (MC) abstracts computability ideas (data structures, operations with them, ways to control and organize these operations, computing models) from the architecture and the functioning of the biological cell, considered alone, and from the ways the cells cooperate in populations like tissues, organs, colonies, including neural cells, hence also the brain.

The growth of MC is impressive. Already in 2000, a series of international meetings was initiated, under the name of Workshop on Membrane Computing (WMC); after the tenth edition, it became Conference on Membrane Computing (CMC). In February 2003, Institute for Scientific Information (ISI) considered $\mathrm{MC}$ as an "emerging research front in computer science" and the paper [8] as a "fast breaking paper". At this moment, the bibliography of MC (see, e.g., http://psystems.disco.unimib.it and http://ppage.psyst ems.eu) counts over 2500 titles, among them having more

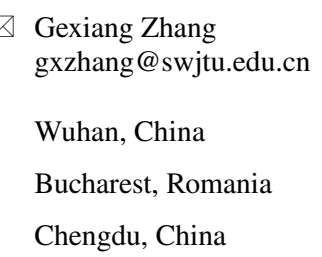

than $100 \mathrm{PhD}$ theses, several monographs $[1-5,7,9,12,13]$, tens of collective volumes and special issues of journals. In 2010, a comprehensive handbook was published by Oxford University Press [10]. Several titles of monographs and collective volumes are provided at the end of this text. Also, the dedicated meetings diversified: there are four yearly meetings, the mentioned CMC, an Asian version of it, ACMC, a Chinese Workshop on Membrane Computing (CWMC) taking place in China, and a yearly Brainstorming Week on Membrane Computing (BWMC), initiated in 2003, in Tarragona, Spain, and after that organized in Seville, Spain. A recent important step in $\mathrm{MC}$ was the creation of The International MC Society (IMCS) in 2016, see the web site http://imcs.org.cn/, aiming to strengthen the international cooperation in this research area. Among the initiatives of IMCS, the publications are of a high priority. From the very beginning, a Bulletin of IMCS was published, online (http:// membranecomputing.net/IMCSBulletin/) and printed, two issues per year. The present Journal of Membrane Computing, abbreviated JMC, is an another important project of IMCS, started under the auspices and with the support of Springer-Verlag.

The JMC provides a forum for developing and nurturing an international community of scholars and practitioners who are interested in all aspects of membrane computing: theories, interdisciplinary areas, applications, and implementations. The journal publishes original, high-quality and previously unpublished research papers, survey and review articles, short communications, and tutorial papers, see https $: / /$ www.springer.com/computer/theoretical+computer+scien ce/journal/41965. JMC welcomes high-quality submissions that contribute to the full range of membrane computing research, from cell-like P systems, tissue P systems, spiking neural $\mathrm{P}$ systems, and other types of $\mathrm{P}$ systems, to membrane algorithms, computational complexity, interdisciplinary research combining membrane computing and evolutionary computing and neural networks, to applications like optimization and biosystem modeling, and membrane computing implementations with nanotechnology. This uniquely broad range facilitates the cross-fertilization of ideas between biological and technological studies, and helps to spur on the 
advancement of an interdisciplinary community that is interested in biologically inspired computational intelligence.

It is important to stress the fact that JMC is centered on $\mathrm{MC}$, but its scope is much larger: any topic even remotely related with MC is of interest. We mention here, only as illustrating examples, areas such as (distributed) evolutionary computing, neural computing, reaction systems, parallel and distributed computing, bio-inspired computing in general. This aspect is also related to our belief, already suggested before, that biology is evolving towards something like infobiology, infobiotics, which will incorporate and in which several current branches of natural computing (such as DNA and membrane computing) will get, partially or totally, "dissolved".

The JMC editorial board, consisting of Honorary Editorin-Chief, Editor-in-Chief, Managing Editor and 17 members, represents experts in a range of fields, including theoretical computer science, engineering, mathematics, bioinformatics, and nanotechnology. These absolutely first-rate editorial board members, listed on the inside cover page of this issue, are responsible for dealing with the reviews of regular papers, including the recommendations on the acceptance or rejection of papers and the improvement of papers quality by providing a constructive and timely review process.

We hope to have a successful journal, we are determined to work in this direction doing our best, and we invite the readers and the collaborators to join us. Please submit papers to JMC at the web site http://www.springer.com/41965, where instructions for authors are available. Welcome to download, read, cite and propagate the papers published in this journal. Everyone can free access in 2019 and 2020. If you encounter any difficulties, please contact the Journal Editorial Office Senior Editor (celine.chang@springernature.com) or Assistant Editor (jane.li@springer.naturecom), or Editor-in-Chief (lqpanhust@gmail.com) or Managing Editor (gexiangzhang@gmail.com).

We are deeply grateful to Springer-Verlag, in particular, to Beijing chapter of Springer, for the highly professional and pleasant cooperation.

\section{References}

1. Ciobanu, G. (2010). Membrane computing. Biologically inspired process calculi. Iaşi: The Publ. House of Al.I Cuza Univ.

2. Ciobanu, G., Păun, Gh., \& Pérez-Jiménez, M.J. (Eds.). (2006). Applications of membrane computing. Berlin: Springer.

3. Florea, A.G., \& Buiu, C. (2017). Membrane computing for distributed control of robotic swarms: emerging research and opportunities. Pennsylvania: IGI Global.

4. Frisco, P. (2009). Computing with Cells: advances in membrane computing. Oxford: Oxford Univ. Press.

5. Frisco, P., Gheorghe, M., \& Pérez-Jiménez, M.J. (Eds.). (2014). Applications of membrane computing in systems and synthetic biology. Berlin: Springer.

6. Kari, L., \& Rozenberg, G. (2008). The many facets of natural computing. Communications of the ACM, 51(10), 72-83.

7. Manca, V. (2013). Infobiotics: information in biotic systems. Berlin: Springer.

8. Păun, Gh. (2000). Computing with membranes. Journal of Computer and System Sciences, 61(1):108-143; Turku center for computer science-TUCS report no. 208, 1998 (www.tucs.fi).

9. Păun, Gh. (2002). Membrane computing. An introduction. Berlin: Springer (translated in Chinese in 2012).

10. Păun, Gh., Rozenberg, G., \& Salomaa, A. (Eds.). (2010). The Oxford handbook of membrane computing. Oxford: Oxford University Press.

11. Rozenberg, G., Bäck, T.H., \& Kok, J.N. (Eds.). (2012). Handbook of natural computing (Vol. 4). Berlin: Springer.

12. Zhang, G., Cheng, J., Wang, T., Wang, X., \& Zhu, J. (2015). Membrane computing: theory and applications. Beijing: Science Press.

13. Zhang, G., Pérez-Jiménez, M.J., \& Gheorghe, M. (2017). Real-life applications with membrane computing. Berlin: Springer. 